\title{
Influence of the collision speed and angle of a bullet: experimental reconstruction of bullet configuration and FE-analysis
}

\author{
H. Sakamoto ${ }^{1}$, T. Hiwatashi ${ }^{1}$, T. Yamaguchi ${ }^{2}$ \& M. Yamamoto ${ }^{3}$ \\ ${ }^{1}$ Mechanical System Division, \\ Graduate School of Science and Technology, Kumamoto University, \\ Japan \\ ${ }^{2}$ Forensic Science Laboratory, Kumamoto Pref. Police H.Q., Japan \\ ${ }^{3}$ Faculty of Engineering, Kumamoto University, Japan
}

\begin{abstract}
In this research, the bullet-firing test was carried out at different velocities and collision angles of the bullet. The influence of its velocity and angle on the deformation shape after firing was discussed by comparison with experiment and simulation. The velocity of the bullet was chosen in several kinds of speed ranges at $80 \mathrm{~m} / \mathrm{s}-250 \mathrm{~m} / \mathrm{s}$. As for the angle of incidence with the collision object, four kinds of angles $90^{\circ}$ (head-on collision), $45^{\circ}, 30^{\circ}$ and $60^{\circ}$ were set. The deformation shape was measured by a $3 \mathrm{D}$ coordinate measurement machine and reconstructed with 3D-CAD based on the 3D digital data. The bullet hole and deformation of the polycarbonate board caused by the bullet's collision with the object was also examined. In addition, the collision simulation of the bullet was carried out using LS-DYNA, and these analytical results were compared with the 3D digital data of the bullet. The comparison of the FE-simulation analysis results of the experiment enabled the quantitative evaluation of the collision deformation.
\end{abstract}

Keywords: collision, bullet, deformation analysis, LS-DYNA, 3D-CAD.

\section{Introduction}

Gun crime has been increasing year on year. Collecting the bullet after firing is needed to solve these affairs [1]. It is often that a bullet is the only evidence in the affair. Therefore, studies about a bullet deformed by a collision are very 
important. For example, rifling marks on a bullet after firing give information about the type of gun used; in the same way, deformation of the target will indicate the firing position and firing angle. The purpose of this research is to clarify the influence of collision velocity and collision angle on deformed shapes of bullets and targets. In addition, we simulated the collision of the bullet by FEM (Finite Element Method) and attempted a comparison between experimental and simulated results.

\section{Experiment}

\subsection{Materials}

Three types of bullet with full metal were used. The external appearances are shown in Figure 1. These are called "round nose bullet" and the lead core is coated with copper film. Bullets were shot with 38Auto and Wheel (S\&W) gun (Figure 2) at a polycarbonate plate (PC), which was used as a shield. PC board of $10 \mathrm{~mm}$ in thickness was used.

\subsection{Experimental procedure}

The distance from gun to target was about $6.4 \mathrm{~m}$ shown in Figure 3 . The velocity of the bullet was measured by a laser ballistic chronograph. The bullet velocity was controlled by adjusting the amount of explosive powder in the cartridge case. The 25AUTO and 380AUTO shown in Figure 1 (b)(c) were used in headon collision tests. The 38SPL shown in Figure 1(a) was used in oblique collision tests. The collision angles are $\boldsymbol{\theta}=30^{\circ}, 45^{\circ}$ and $60^{\circ}$ to the target shown in Figure 4.

\section{Results and discussion}

\subsection{Test firing}

The upper part in Figure 5 shows the bullet's original shape and deformed shapes in the case of head-on collision after firing. The corresponding bullet holes of the target plate were shown in the lower part. These configurations were precisely measured by a $3 \mathrm{D}$ coordinate measurement machine and were reconstructed by using a 3D-CAD system as digital data as shown in Figure 6. The reconstructed models of the deformed bullet were done to compare experimental and analytical results quantitatively. Moreover, by using the digital data, the deformed bullet's dimensions, for example, cross sectional areas and volumes, can be evaluated precisely.

Figure 7 shows the relationship between the bullet velocity and deformation rate. This indicates that the deformation rate's peak occurs at $150 \mathrm{~m} / \mathrm{s}$ (corresponding to a kinetic energy of $100 \mathrm{~J}$ ). The reason comes from the fact that the compressive strength of the bullet overtakes the compressive strength of polycarbonate in the case of the low collision velocity (less than $150 \mathrm{~m} / \mathrm{s}$ ). The relationship between velocity and bullet hole are given in Table 1 . The depth of 
the bullet hole becomes bigger with increasing collision velocity. The diameter of the bullet also shows a similar trend. The depth of the bullet hole is comparatively small due to energy absorption by bending deformation of the polycarbonate. However, in the case of high velocity (more over $150 \mathrm{~m} / \mathrm{s}$ ), the plastic deformation region was limited to the contact region only. Therefore, both bullet hole diameter and compressive plastic deformation of the bullet have been decreased at $251 \mathrm{~m} / \mathrm{s}[2,3]$.

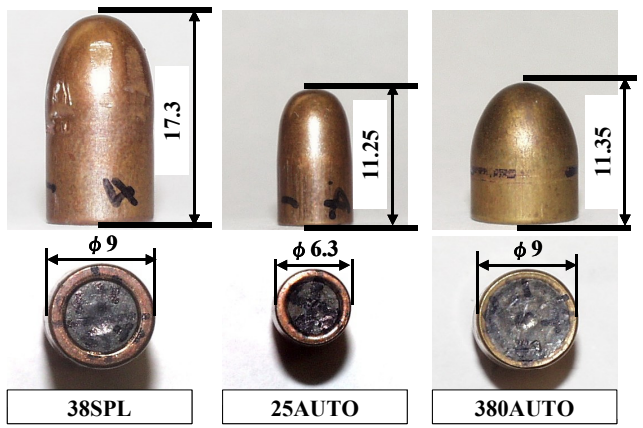

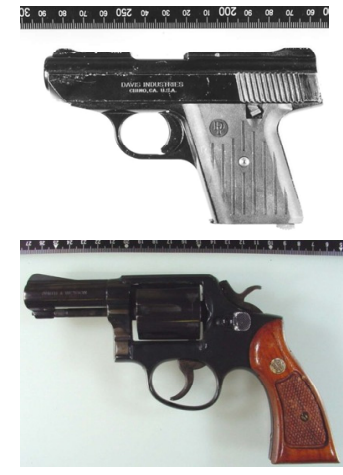

Figure 1: Geometry and dimension of Figure 2: 38Auto and Wheel bullets.
(S\&W) gun.

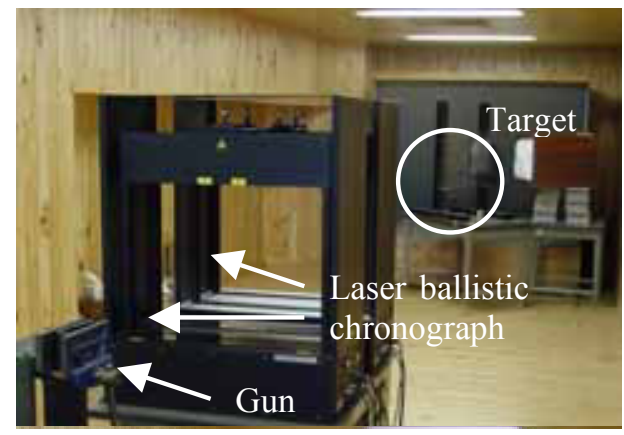

Figure 3: $\quad$ Firing experimental layout.

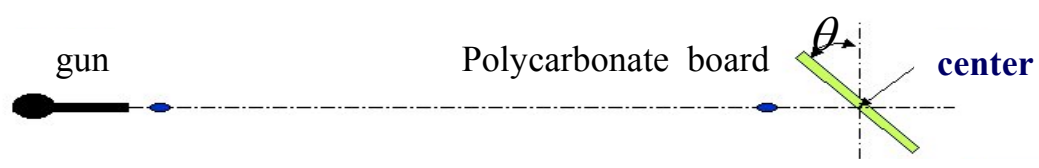

Overhead view

Figure 4: Overhead view of firing experiment system. 


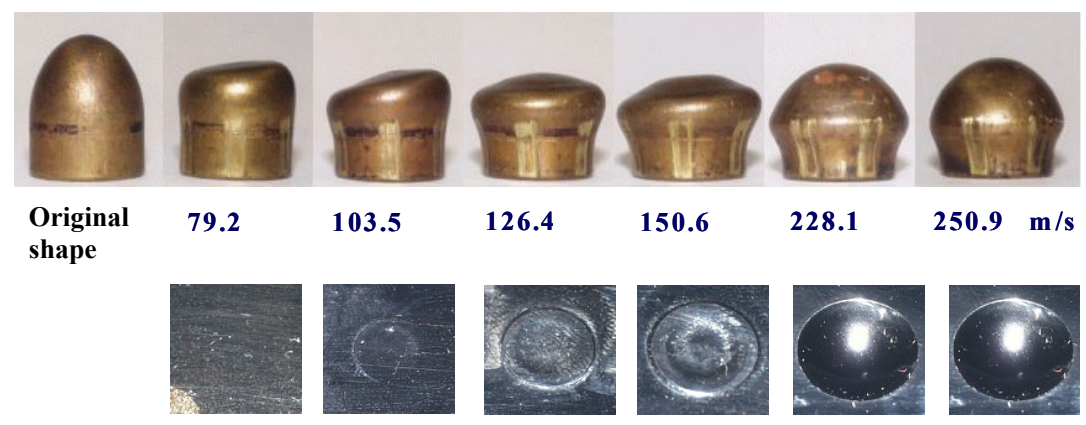

Figure 5: Bullet's shapes and bullet's holes (head-on collision, 380AUTO, $\mathrm{V}=79.2 \sim 250.9 \mathrm{~m} / \mathrm{s}$ ).

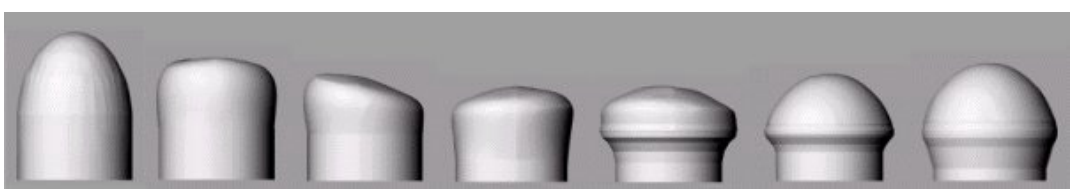

Figure 6: Reconstruction bullet shape by using 3D measurement and 3DCAD.

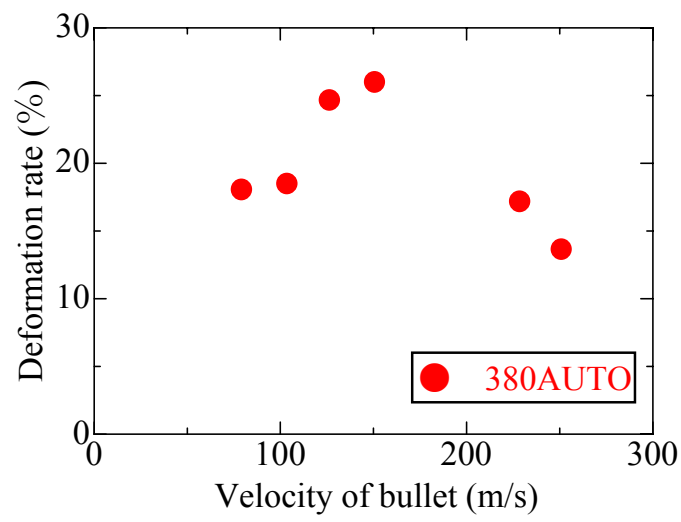

Figure 7: Relationship between bullet velocity and deformation rate (head-on collision).

\subsection{Numerical simulation}

Finite Element models for the bullet and polycarbonate plate are shown in Figure 8. As analysis conditions, the collision velocities and the angles in experimental conditions were used. In addition, the spinning of the bullet, material's strain rate 
dependence, Mach number and friction were considered [3-6]. The main analytical constants of the material properties used in the simulation experiment are shown in table 2 .

Table 1: The dimensions of bullet holes.

\begin{tabular}{|l|c|c|c|}
\hline \multirow{2}{*}{ Type of bullet } & $\begin{array}{l}\text { Collision } \\
\text { velocity } \\
(\mathrm{m} / \mathrm{s})\end{array}$ & $\begin{array}{l}\text { Diameter of bullet } \\
\text { hole }\end{array}$ & $\begin{array}{l}\text { Depth of bullet } \\
\text { hole } \\
(\mathrm{mm})\end{array}$ \\
\hline \hline \multirow{3}{*}{$\begin{array}{l}\text { 380AUTO } \\
\text { (head-on } \\
\text { collision) }\end{array}$} & 79 & 7.2 & 0 \\
\cline { 2 - 4 } & 104 & 8.3 & 0.1 \\
\cline { 2 - 4 } & 126 & 10.3 & 0.3 \\
\cline { 2 - 4 } & 151 & 11.4 & 0.4 \\
\cline { 2 - 4 } & 228 & 12.2 & 3.9 \\
\hline
\end{tabular}

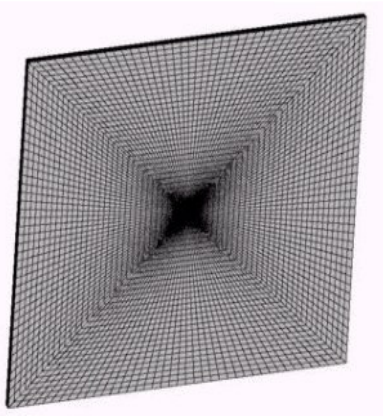

(a) Target model (polycarbonate board)

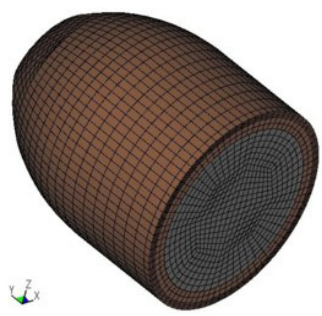

(b) Bullet model (380AUTO)

Figure 8: An example of the analysis model using an FEM simulation.

Table 2: Analytical constants of material properties.

\begin{tabular}{|l|c|c|c|}
\hline & $\mathrm{Cu}$ & $\mathrm{Pb}$ & $\mathrm{PC}$ \\
\hline Mass density $\left(\mathrm{kg} / \mathrm{m}^{3}\right)$ & $8.93 \times 10^{3}$ & $11.337 \times 10^{3}$ & $1.2 \times 10^{3}$ \\
\hline Young's modulus $(\mathrm{GPa})$ & 132 & 17.2 & 2.06 \\
\hline Yield stress $(\mathrm{MPa})$ & 196 & 60 & 100 \\
\hline Poisson's ratio & 0.34 & 0.44 & 0.3 \\
\hline
\end{tabular}

Comparison between analysis results and experimental ones in oblique collision (collision angle $30^{\circ}$ ) are shown in Figure 9. In the case of not considering the strain rate dependence, as the bullet deformation for high velocity is overestimated, the simulation was performed by using the strain-strain relation obtained under different velocity compression tests. 
The deformation shapes obtained from simulation were in good agreement with experimental results for the collision angle of $30^{\circ}$. However, for the angle of 60-degrees, the calculated model and the experimental results were a little different. Although the contact between the bullet bottom part and PC-plate in the experiments was recognized, this contact mark on the PC plate was not observed in the simulation. The same tendency is observed for the collision angle of 45-degrees. This is probably caused by the definition of friction between the bullet and polycarbonate and the bonding condition between lead and copper of the bullet used in the simulation. Results of head-on collisions are not presented here, however experimental results and simulation results show very good correlation.
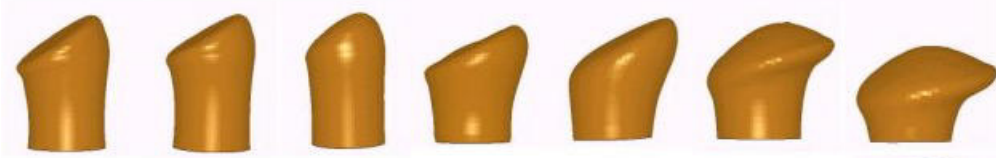

(a) Analysis results in collision angle $30^{\circ}(\mathrm{V}=79 \sim 218 \mathrm{~m} / \overline{\mathrm{s}})$
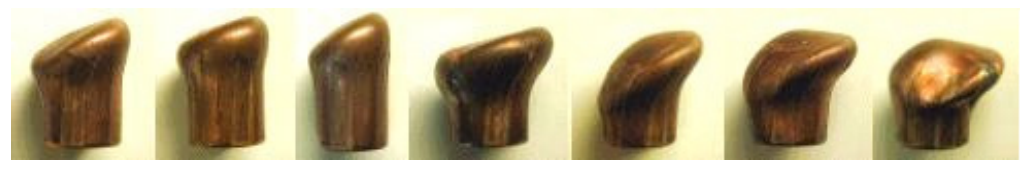

(b) Experiment results in angle $30^{\circ}(\mathrm{V}=79 \sim 218 \mathrm{~m} / \mathrm{s})$

Figure 9: Comparison of analysis results with experiment ones (38SPL, collision angle: $30^{\circ}$ ).

Cracks on copper coated bullets were recognized in oblique collision experiments. These cracks caused by the rifling mark in spirals have little influence on the deformed shape of the bullets shown in Figure 9. However, the non-coated lead bullet breaks with cracks cased along rifling marks in the headon collision experiment (Figure 10). Figure 11 shows an example of the simulation result for the non-coated lead bullet [7,8]. From comparison with both figures, it is found that the deformation and fracture behaviour can be evaluated by simulation quantitatively.

\section{Conclusion}

The effect of collision velocity and collision angle on bullet deformation was discussed and performance of a protection board made of polycarbonate was estimated by experiment and FE Analysis. The results obtained are summarized as follows. 


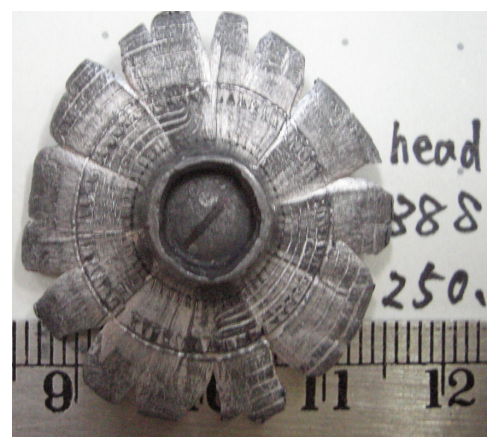

Figure 10: Fracture under head-on collision for non-coated bullet.

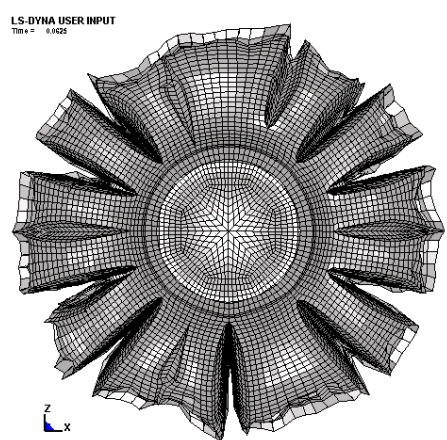

Figure 11: Fracture analysis under head-on collision for noncoated bullet.

(1) For the low collision velocity region, polycarbonate plate undergoes bending deformation. In the case of high collision velocity, the plastic deformation region of polycarbonate plate was limited to the bullet's contact region only.

(2) For a collision angle smaller than $30^{\circ}$, the simulation results show good agreement with experimental ones under consideration of the train rate dependence.

(3) When the collision angle is bigger than $45^{\circ}$, the simulation results and the experimental ones are a little different because of the friction between the bullet and polycarbonate, and the bonding condition between lead and copper.

(4) In collision simulations, the rifling marks on full metal shield bullets of firing have little influence on the deformed shape of bullets. However, the crash and fracture phenomenon occur along the cracks ignited by the rifling marks.

\section{References}

[1] K. Kashiwatani, Forensic science for Investigation, 1983.

[2] N. Cristescu: Dynamic Plasticity, North-Holland Publishing Company, 1967.

[3] T. Borvik, O.S. Hopperstad, T. Berstad, M. Langseth, A computational model of viscoplasticity and suctile damage for impact and penetration, Eur. J. Mech. A/Solids 20, pp.685-712, 2001

[4] T. Negishi, T. Ogura, T. Masumoto, T. Goto, K. Fukuoka, and J. Syono: Mat. Sci. 20,1985.

[5] R. Barauskas \& A. Abraitiene, Computational analysis of impact of impact of a bullet against the multiplayer fabrics in LS-DYNA, International Journal of Impact Engineering, 2005

[6] K. Sakino, Strain Rate Dependence of Dynamic Flow Stress of Aluminum Alloy 6061 at Very High Straom Rates, Original Paper, vol.54 No.12 pp.1301-1306 
116 Computational Methods and Experimental Measurements XIII

[7] H. Kurtaran, M. Buyuk \& A. Eskandarian, Ballistic impact simulation of GT model vehicle door using finite element method, Theoretical and Applied Fracture Mechanics 40,pp.113-121, 2003

[8] P.A. Vityaz, V. Roman: Proc.13th Int. J. Mach. Tool Des. \& Res., 1972. 